\title{
Assessing Dual Sensor Enhanced Flight Vision Systems to Enable Equivalent Visual Operations
}

\author{
Lynda J. Kramer ${ }^{1}$ \\ NASA Langley Research Center, Hampton, VA, 23681-2199, USA \\ Timothy J. Etherington ${ }^{2}$ \\ Rockwell Collins, Cedar Rapids, IA, 52398, USA \\ Kurt Severance ${ }^{3}$, Randall E. Bailey ${ }^{4}$, Steven P. Williams ${ }^{5}$, and Stephanie J. Harrison ${ }^{6}$ \\ NASA Langley Research Center, Hampton, VA, 23681-2199, USA
}

\begin{abstract}
Flight deck-based vision system technologies, such as Synthetic Vision (SV) and Enhanced Flight Vision Systems (EFVS), may serve as a revolutionary crew/vehicle interface enabling technologies to meet the challenges of the Next Generation Air Transportation System Equivalent Visual Operations (EVO) concept - that is, the ability to achieve the safety of current-day Visual Flight Rules (VFR) operations and maintain the operational tempos of VFR irrespective of the weather and visibility conditions. One significant challenge lies in the definition of required equipage on the aircraft and on the airport to enable the EVO concept objective. A motion-base simulator experiment was conducted to evaluate the operational feasibility, pilot workload and pilot acceptability of conducting straight-in instrument approaches with published vertical guidance to landing, touchdown, and rollout to a safe taxi speed in visibility as low as $\mathbf{3 0 0} \mathbf{f t}$ runway visual range by use of onboard vision system technologies on a Head-Up Display (HUD) without need or reliance on natural vision. Twelve crews evaluated two methods of combining dual sensor (millimeter wave radar and forward looking infrared) EFVS imagery on pilot-flying and pilot-monitoring HUDs as they made approaches to runways with and without touchdown zone and centerline lights. In addition, the impact of adding SV to the dual sensor EFVS imagery on crew flight performance, workload, and situation awareness during extremely low visibility approach and landing operations was assessed. Results indicate that all EFVS concepts flown resulted in excellent approach path tracking and touchdown performance without any workload penalty. Adding SV imagery to EFVS concepts provided situation awareness improvements but no discernible improvements in flight path maintenance.
\end{abstract}

\section{Introduction}

$\mathrm{T}$

HE U.S. air transportation system is undergoing a transformation to accommodate the movement of large numbers of people and goods in a safe, efficient, and reliable manner. ${ }^{1}$ One of the key capabilities envisioned to achieve this Next Generation Air Transportation System (NextGen) is the concept of equivalent vision operations (EVO). EVO is the ability to achieve the safety of current-day Visual Flight Rules (VFR) operations and maintain the operational tempos of VFR irrespective of the weather and visibility conditions.

One significant challenge for EVO is the definition of required equipage on the aircraft and on the airport. With today's equipment and regulations, significant investment is required in on-board equipment for navigation, surveillance, and flight control and on the airport for precision guidance systems and approach lighting systems for "all-weather" landing capability. The levels of equipment redundancy, capability, maintenance, performance, and

${ }^{1}$ Aerospace Engineer, Crew Systems and Aviation Operations Branch, MS 152, Non-member.

${ }^{2}$ Engineering Technical Fellow, Advanced Technology Center, 100 Collins Road, Non-member

${ }^{3}$ Computer Engineer, Flight Software Systems Branch, MS 472, AIAA Associate Fellow.

${ }^{4}$ Lead Aerospace Engineer, Crew Systems and Aviation Operations Branch, MS 152, Non-member.

${ }^{5}$ Research Engineer, Crew Systems and Aviation Operations Branch, MS 152, Non-member.

${ }^{6}$ Aerospace Research Engineer, Crew Systems and Aviation Operations Branch, MS 152, Non-member.

American Institute of Aeronautics and Astronautics 
crew training dramatically increase as landing visibility minima decrease. A vivid demonstration of the current complexity (and cost) to meet "weather and visibility-independent" capability is to look at the present National Air Space infrastructure. As of April 2015, there were 1,277 Instrument Landing System (ILS) instrument approach procedures (IAPs) to Category I minima (no lower than $200 \mathrm{ft}[61 \mathrm{~m}]$ decision height, $2400 \mathrm{ft}[731.5 \mathrm{~m}]$ visibility) available throughout the United States, but only 153 Category II (no lower than $100 \mathrm{ft}$ [30.5 m] decision height, 1200 $\mathrm{ft}[366 \mathrm{~m}]$ visibility) and 118 Category III (a decision height lower than $100 \mathrm{ft}$, or no decision height, or a runway visual range (RVR) less than $1200 \mathrm{ft}$ ) IAPs. ${ }^{2}$

In conjunction with the ILS sophistication, approach lighting systems of increasing complexity are required as landing visibility minima decrease. Typical for Category I precision approaches is the MALSR (Medium Intensity Approach Lighting System with Runway Alignment Indicator Lights) approach lighting system (ALS) and for Category II/III instrument approaches, the ALSF-2 (High Intensity Approach Lighting System with Sequenced Flashing Lights). An ALS provides the visual information for runway alignment, height perception, roll guidance, and horizontal references.

EVO implies "Category III" operations to all runway thresholds. Synthetic Vision Systems (SVS) and Enhanced Flight Vision System (EFVS) flight-deck based technologies offer a means of providing EVO capability without significant airport infrastructure investment while potentially increasing efficiency and throughput during low visibility operations. NASA Langley Research Center is conducting research to ensure effective technology development and implementation of regulatory and design guidance to support introduction and use of onboard SVS/EFVS advanced flight deck vision system technologies in NextGen operations.

\section{Background}

SVS is a computer-generated image of the external scene topography that is generated from aircraft attitude, highprecision navigation, and data of the terrain, obstacles, cultural features, and other required flight information. EFVS is a real-time electronic image of the external scene generated by imaging sensors, such as a Forward-Looking InfraRed (FLIR) or Millimeter Wave Radar (MMWR), and presented on a head-up display (HUD). Both SVS and EFVS are onboard vision-based technologies intended to supplement or enhance the natural vision of the pilot in low visibility conditions. Combined Vision Systems (CVS) use a combination of SVS and EFVS for presentation to the pilot.

NASA and others have developed and shown that SVS technologies provide significant improvements in terrain awareness and reductions for the potential of Controlled-Flight-Into-Terrain incidents/accidents, ${ }^{3,4}$ improvements in flight technical error to meet Required Navigation Performance criteria, ${ }^{5-7}$ and improvements in situation awareness without increased workload compared to current generation cockpit technologies. ${ }^{8-10}$ As such, SVS, often displayed on a head-down display (HDD), is emerging as standard equipage for Part 23 and Part 25 flight decks even though, to date, no operational credit is obtained from equipage. ${ }^{11}$

EFVS capability on a HUD using FLIR sensor technology has garnered a significant share of the business aircraft market and is growing in Part 121 and 135 operations. ${ }^{12}$ EFVS provides many of the same operational benefits as SVS technology, but it uses a real-time view of the external environment, independent of the aircraft navigation solution or database. These differences, in part, enable operational credit with use of an approved EFVS. In 2004, Title 14 of the Code of Federal Regulations (CFR) Section ( $(9)$ 91.175 was amended to enable operators conducting straight-in IAPs (in other than Category II or Category III operations) to descend below the published Decision Altitude (DA), Decision Height (DH) or Minimum Descent Altitude (MDA) down to 100 feet (ft) above touchdown zone elevation (TDZE) using an approved EFVS in lieu of natural vision. (To descend below 100 feet above the TDZE, the required visual references for landing must be distinctly visible and identifiable by the pilot using natural vision.) An approved EFVS must meet the requirements of $\S 91.175(\mathrm{~m})$ and the use of a HUD or an equivalent display is essential.

Synthetic and Enhanced Vision Systems (SEVS) technologies, such as SVS/EFVS in combination with HDD/HUD, form the basis for an electronic display of visual flight references for the flight crew. Integrating these SEVS displays with conformal symbology provides important situation, guidance, and/or command information as necessary and/or appropriate to enable all weather approach and landing operations. The primary reference for maneuvering the airplane is based on what the pilot sees electronically through the SEVS, in lieu of or supplemental to the pilot's natural vision, in low visibility conditions.

The key concept for 14 CFR $\S 91.175$ is that an EFVS can be used in lieu of natural vision from the DA/DH/MDA to $100 \mathrm{ft}$ height above the TDZE provided the visibility of the enhanced vision image meets or exceeds the published visibility required for the approach being flown and the required visual references are clearly identified. Minimum aviation system performance standards for EFVS are available in RTCA DO-315 ${ }^{13}$. RTCA DO-315 also provides performance standards for SVS but without operational credit.

American Institute of Aeronautics and Astronautics 
The FAA has started a rulemaking project ${ }^{14}$ to expand operational credit for EFVS beyond what is currently authorized under 14 CFR $\S 91.175$. Specifically, the new regulation (14 CFR §91.176) will cover instrument approaches with EFVS, enabling landings without natural vision. The proposed rule would permit an EFVS to be used in lieu of natural vision during a straight-in precision IAP (Category I, II and III) or an approach with approved vertical guidance. Current EFVS operations are limited to straight-in instrument approaches procedures (in other than Category II or Category III operations). The new rule would permit EFVS to be used during touchdown and rollout and would also add operational benefits for Part $91 \mathrm{~K}, 135$, and 121 operators. FAR $\S 135.219$ would be amended to allow dispatch to a destination that is below minimums if the aircraft is EFVS-equipped and the operator is authorized for EFVS operations through OpSpecs (Operations Specifications), MSpecs (Management Specifications), or LOA (Letters of Authorization). Also, FAR §135.225 would be modified to enable an EFVS-equipped aircraft and trained crew to initiate or continue an approach when the destination airport is below authorized minimums. These upcoming rule changes support EVO through use of an onboard flight-deck based EFVS rather than necessitating additional ground infrastructure equipment and operating procedures. An EFVS-equipped aircraft and qualified crew could dispatch and continue an approach to a landing, even when the destination airport is below authorized minimums, solely through the use of an electronic (sensor) image since natural vision is no longer required with EFVS. ${ }^{15}$

The FAA proposed EFVS rule change does not explicitly impose a RVR limitation but mentions that initial implementations of EFVS operations to touchdown and rollout may be limited to visibilities of no lower than 1000 RVR because airworthiness and certification criteria have not been developed to support EFVS operations below 1000 RVR. Past NASA simulation research ${ }^{16}$ supports the viability of this expanded EFVS operational credit where it was shown that using a single sensor EFVS (FLIR imagery on a HUD) to hand-fly approaches through touchdown resulted in excellent localizer tracking performance and an improvement in glideslope tracking performance in visibility as low as 1000 RVR. All currently approved EFVS ${ }^{14}$ use FLIR (single sensor imagery) on a HUD. Natural vision of 700 to $1000 \mathrm{ft}$ RVR has been shown to be sufficient to mitigate a complete failure of the single sensor EFVS. FLIR is dependent upon atmospheric conditions. It works well in smoke, haze and at night, but has degraded performance in some fog, rain, and snow conditions. ${ }^{17}$

RTCA DO- $341^{18}$ was drafted to establish minimum performance standards for EFVS operations on straight-in IAPs with published vertical guidance to touchdown, landing, and roll-out to a safe taxi speed in visibility as low at $300 \mathrm{ft}$ RVR. In this operation, criteria are established such that the combination of all systems used during the EFVS operation shall be designed, tested, and certified to a level of safety appropriate for the phase of flight and the intended operation. As such, a fail-operational EFVS design is necessary - consistent with other systems and subsystems used for the same intended function and phase of flight (e.g., Cat. III instrument landing systems, autoland systems, and navigation systems) - without the need or reliance of the crew's natural vision. In these extremely low visibility conditions, there is not sufficient natural vision for the flight crew to mitigate certain EFVS failure conditions which might have catastrophic consequences.

DO-341 specifies that both the pilot-flying (PF) and pilot-monitoring (PM) are required to have an independent EFVS HUD as well as an alternate display for enhanced vision (EV) sensor imagery. It is envisioned that more than one sensor will be needed for EFVS operations below $1000 \mathrm{ft}$ RVR. FLIR sensor technology used in production EFVS is limited in its ability to work in extreme low visibility conditions (e.g., $<700 \mathrm{ft} \mathrm{RVR}$ ). ${ }^{17,19}$ MMWR technologies show promise for working in nearly all operationally relevant atmospheric conditions but the image resolution is not as good as natural vision.

A motion-based simulation experiment was conducted to evaluate the operational feasibility, pilot workload, and pilot acceptability of conducting straight-in instrument approaches with published vertical guidance to landing, touchdown, and rollout to a safe taxi speed in visibility as low as $300 \mathrm{ft}$ runway visual range by use of vision system technologies (EFVS and SVS) on a head-up display without need or reliance on natural vision. Twelve crews evaluated two methods of combining dual sensor (MMWR and FLIR) EFVS imagery on PF and PM HUDs. In addition, the crews evaluated three CVS HUD concepts to assess the complementary use of SVS which is unaffected by weather or time of day and EV sensors which offer real-time imaging detection of objects not in the SVS database. An ILS was used for approach guidance and a simulated Global Positioning System/Wide Area Augmentation System was used for the navigation component of the on-board SVS. Crews also assessed dual sensor EFVS/CVS HUD concepts during taxi and departure operations in $300 \mathrm{ft}$ RVR. Another key element of the testing entailed investigating the crew's awareness and reaction to non-normal events (e.g., EFVS HUD failure) that were unexpectedly introduced into the experiment. These non-normal events are critical determinants in the underlying safety of all-weather operations.

This paper documents crew approach/landing performance, workload, situation awareness, and crew-preferred HUD concepts for a dual sensor (FLIR and MMWR) EFVS, with and without Synthetic Vision (SV), during extremely low visibility approach and landing operations. Due to paper length, dual sensor EFVS/CVS departure performance and crew decision making during a non-normal event are addressed in a separate publication. ${ }^{20}$

American Institute of Aeronautics and Astronautics 


\section{Methodology}

\section{A. Subjects}

Twenty-four pilots ( 12 crews total), representing 5 airlines ( 7 crews), a cargo carrier ( $1 \mathrm{crew})$ and business aviation ( 4 crews), participated in the experiment. Crews were paired by airline to ensure crew coordination and cohesion with regard to operating procedures. All subjects were Airline Transport Pilot rated, had at least 100 hours of HUD experience as pilot in command, and had prior EV or EFVS experience. All subjects were male. The Captains' average age was 57.7 years and with an average of 1,988 HUD flight hours, 23 years of commercial flying and 14.8 years of military flying. The First Officers' average age was 49.7 years and with an average of 1,255 HUD flight hours, 14.8 years of commercial flying and 14 years of military flying. The Captain was the designated PF throughout all the trials and the First Officer served as the PM.

\section{B. Simulator}

The experiment was conducted on the motion-base in the Research Flight Deck (RFD) simulation facility at NASA Langley Research Center (Figure 1). The RFD is configured with four 10.5-inch Vertical (V) by 13.25-inch Horizontal (H), 1280x1024 pixel resolution color displays, tiled across the instrument panel. The RFD also includes dual Rockwell Collins HGS-6700 HUDs (one for PF and one for PM), Mode Control Panel, Flight Management System, and Electronic Flight Bags for PF and PM. Two 5-camera Smart Eye ${ }^{\mathrm{TM}}$ head and eye tracking systems are installed to quantify both crew member's head movement and eye-gaze behavior. Both eye tracking systems data outputs and the simulator state data output are time-synchronized.

The full-mission RFD simulates a Boeing B-757-200 aircraft, albeit controlled through sidestick inceptors. The pilot and co-pilot inceptors are directly linked as if mechanically connected. A collimated out-the-window (OTW) scene is produced by an Evans and Sutherland Image Generator (IG) graphics system providing approximately 200 degrees (deg) $\mathrm{H}$ by 40 deg $\mathrm{V}$ field-of-view (FOV) at 26 pixels per degree.

The sidestick inceptor force gradients and deflection characteristics mimic the Airbus A-320 aircraft. A ratecommand attitude hold fly-by-wire control law, coded in Matlab/Simulink, was installed for this test. The pilot and co-pilot inceptors are directly linked as if mechanically connected.

The auto-throttle system backdrives the throttle handles to directly reflect the power setting commanded to the engines. Take-off, go-around (TOGA) buttons and autothrottle disconnect buttons are placed on the throttle handles.

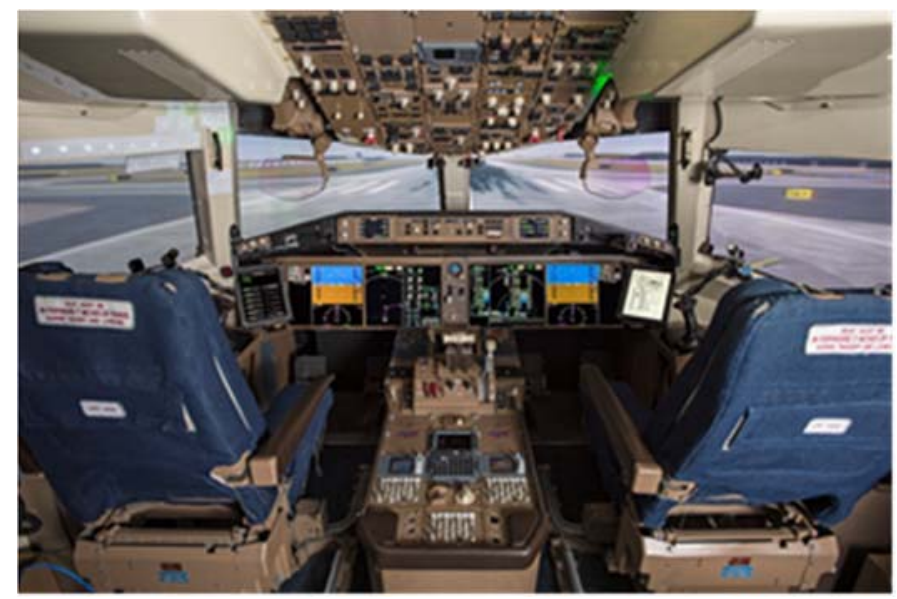

Figure 1. Research Flight Deck Simulator with dual HUDs and Head-Down Instrument Panel.

\section{Simulator Database}

Operations were simulated at Memphis International Airport (FAA identifier: KMEM). The simulation was built around FAA source data for KMEM, valid from 16 November 2012 to 13 December 2012. These data were used to develop all flight plans, scenarios, approach paths, and OTW, SV and EV databases. Day simulations were flown, with the weather tailored to create the desired visibility conditions.

Testing included an experimental variation of airport lighting configurations (Type I vs. Type III). Testing using a MALSR ALS without touchdown zone/centerline (TDZ/CL) lights, typical of a Category I/Type I operations

American Institute of Aeronautics and Astronautics 
runway, was conducted on KMEM Runways 18L, 18C, and 18R. Testing using an ALSF-2 ALS with TDZ/CL lights, typical of a Category III/Type III operations runway, was conducted on Runways 36L, 36C, and 36R.

All runways included high intensity runway lights and serviceable centerline and surface markings. Airport lighting was drawn using calligraphics.

\section{SVS Simulation}

The SVS terrain consisted of a gridded terrain structure derived from digital terrain elevation data (DTED) Level 2 (approximately 90 meter spacing). The terrain model was smoothly shaded with an elevation-based color texture generated from higher resolution DTED Level 1 data (approximately 30 meter spacing) which extends 200.12 nautical miles $(\mathrm{nm})$ in the east/west direction by $180.99 \mathrm{~nm}$ in the north/south direction centered at KMEM Runway 36C. On both the HUD and primary flight display (PFD), a one kilometer spacing terrain conformal grid was superimposed on the terrain. The grid was cut out around the perimeter of the airfield. Grid lines were $50 \%$ transparent and 4 pixels wide. Grid cells became visible at $5 \mathrm{~nm}$ from the eye point. On the HUD, the grid was black; whereas on the PFD, a muted green color was used.

For the SVS airfield depiction, both the HUD and PFD used the runway and taxiway geometry from the OTW database. On the HUD, this was all drawn opaque black, with no markings, so that the simulated OTW (i.e., realworld) runways and taxiways would not be obscured by imagery. On the PFD, the original taxiway and runway textures were replaced with representative colors obtained from the original OTW textures, with runway markings included in white. Taxiway markings were excluded.

On the navigation display (ND), the runway, taxiway, and building geometry from the OTW database was flattened, and runway, taxiway, and building textures were replaced with colors which have been used in the past -gray runways, darker gray taxiways, and blue building areas. All runway, taxiway, and other ground markings were included using colors representative of the real-world paint schemes. Taxiway and miscellaneous other markings were made switchable, and turned on and off automatically based on selected map range.

\section{FLIR Simulation}

The FLIR real-time simulation is created by the Evans and Sutherland EPX sensor simulation program. The KMEM database was instantiated with material code properties. From this database, a physics-based InfraRed (IR) sensor simulation, interacting with this material-coded database and the simulated weather conditions was used to test various experimental conditions. The FLIR simulation approximates the performance of a state-of-the-art EVS by modeling a short-wave, mid-wave $\sim 1.0$ to 5.0 micron infrared detector.

\section{MMWR Simulation}

The MMWR simulation was created by Unisys Corp under contract to NASA Langley. It simulates a MMWR (30-94 GHz bandwidth) using OpenSceneGraph. The MMWR simulation was created from the same source data used to generate the OTW and FLIR sensor. From this database, the physics-based model used the material coding information to generate simulated radar returns in a perspective three-dimensional azimuth/elevation (C-Scope) format of a two-dimensional azimuth/range (B-Scope) radar display using physical MMWR radar characteristics. A materialclassified visual database allowed the radar return characteristics to be computed on a per-pixel basis using the classic radar range equation. User-defined reflectivity and back scattering coefficients, various parameters defining the radar system, gain adjustments and user-supplied noise textures allowed the system to be tailored to provide a realistic physics-based simulation. Radar parameters simulated a $94 \mathrm{GHz}$ radar with a 2 mile range, using 5 meter range bins and 0.5 deg angular width, simulating emerging 3-dimensional MMWR systems.

\section{Video combiner system}

A high-performance general-purpose programmable computer, referred to as the Video Combiner System (VCS) was designed specifically for this experiment to perform real-time video acquisition, image blending, and feature enhancement for either heads-down or heads-up displays. The VCS is equipped with 12 liquid-cooled central processing unit cores, four independent frame grabbers, an NVIDIA graphics card, and the Windows ${ }^{\circledR} 7$ operating system. Real-time video acquisition is achieved through the use of high-definition Matrox frame grabbers capable of acquiring full-color digital video at up to $1280 \times 1024$ resolution and 60 frames per second. These frame grabbers acquire the three component video feeds from the independent imagery sources: the SVS, FLIR, and MMWR.

Two different methods of combining the FLIR and MMWR imagery, referred to as Blended and Slant Range, were explored in this experiment. The two methods provided experimental variation of the information content (i.e., pilot awareness of imagery sources) and the resultant image contrast.

The Blended method was the simplest image combination performed by the VCS where the FLIR and MMWR imagery were aligned to one another and averaged together. Since image blending often results in a loss of contrast, the Contrast-Limited Adaptive Histogram Equalization (CLAHE) contrast algorithm was applied in real-time to reveal

American Institute of Aeronautics and Astronautics 
the salient features of the scene. The method provides good image contrast without obvious distinction of the image data sources.

As an alternative to a blended-average of the FLIR and MMWR sensors, the VCS also implements a method called Slant Range. The general idea behind this method is that each sensor works best within a nominal slant-range distance from the aircraft given the current RVR conditions. The MMWR characteristics were fixed, and thus, its performance including maximum and minimum range was invariant within the weather and atmospheric properties in this simulation. The FLIR simulation was tuned to characterize measured flight test performance data. Using these guidelines, FLIR (point light sources) provided good detection in front of the aircraft to about 2.5 times the measured $\mathrm{RVR}$, followed by MMWR with an effective range to $2.0 \mathrm{~nm}$. The VCS received state data during the simulation and was therefore aware of the current RVR conditions and aircraft altitude. With this information, the VCS computed slant range distance at every portion of the image and subsequently layered the imagery. The FLIR was shown in the image region closest to the aircraft, followed by only MMWR out to $2.0 \mathrm{~nm}$. A small region of imagery overlap was blended between FLIR and MMWR to lessen the seams in the image. The method provides non-uniform image contrast but with more obvious distinction of the image data sources.

To alleviate aliasing effects in the EFVS HUD imagery, a fast smoothing operation was applied to both the Blended and Slant Range methods.

\section{Audio effects}

Pre-recorded simulated Air Traffic Control (ATC) and air traffic radio were played over the flight deck speakers. The radio calls corresponded to OTW traffic. The intent was to add realism to the test and to introduce some "partyline" radio to add traffic awareness as per normal operations.

Altitude call-outs were played over the flight deck speakers. The automatic altitude calls-out started at "500 feet" (i.e., $500 \mathrm{ft}$ above the TDZE). The "approaching minimums" and "minimums" call-outs were at $100 \mathrm{ft}$ above and at the DA/DH. Flare "prompts" in the form of additional altitude call-outs were used on all runs ("100," "50," "40," "30," "20," and " 10 " at the corresponding radar altitudes in feet).

\section{Head-down displays}

Figure 1 shows the simulator's four main instrument panel displays: a) PF left display, including PFD; b) PF right display including ND; c) PM left display, including ND; and, d) PM right display, including PFD. Each display panel is 13.25 inches $\mathrm{H}$ by 10.5 inches $\mathrm{V}$ which, when viewed from 25 inches, subtends an angular area 30 deg $\mathrm{H}$ by 24 deg $\mathrm{V}$.

\section{Head-up display}

The HGS-6700 HUD is collimated and subtends approximately 40 deg $\mathrm{H}$ by $30 \mathrm{deg}$ V FOV. The HUD projects the imagery from a liquid crystal display in raster format. The video input to the HUD was either EV imagery or combined SV/EV imagery. Standard HGS 6700 HUD symbology (flight path angle marker, guidance cue, glide slope reference line, airspeed/altitude tapes, roll scale, ILS course deviation indicators, vertical speed, radar altimeter, and mode enunciators) enhanced with a runway outline was employed in this experiment. Prior to commencing an approach, crews entered the descent angle (all were $3 \mathrm{deg}$ ), length, and elevation of the runway of intended landing so that a conformal runway outline was drawn around it. HUD brightness, contrast, and declutter controls were provided to the pilot but these were set-up and held constant for all pilots to avoid experimental confounds.

A $20 \mathrm{deg} \mathrm{H}$ by $15 \mathrm{deg} \mathrm{V}$ sensor window was used to display HUD EV imagery. The sensor window, which is significantly smaller than the HUD FOV, matches the minimum FOV as per RTCA DO-315 and DO-341.

\section{Independent Variables}

1. HUD Vision System (VS) Concepts

Two operational baseline HUD concepts, representing approved HUD operations in today's National Airspace System, were tested while flying instrument approaches at KMEM.

The first operational baseline concept was a conventional HUD (symbology only, no EV) flown in $1800 \mathrm{ft}$ RVR which is the lowest visibility authorized to manually fly a HUD for Category (Cat) 1 approach with $200 \mathrm{ft} \mathrm{DH}$.

The second operational baseline concept was a FLIR EFVS which is the only currently certified EFVS, flown in $1000 \mathrm{ft} \mathrm{RVR}$. The EV imagery (FLIR) shown on the HUD was confined to the $20^{\circ} \mathrm{H} \mathrm{x} 15^{\circ} \mathrm{V}$ sensor window.

Five dual sensor (MMWR and FLIR) HUD Vision System (VS) concepts (2 EFVS, 3 CVS) were evaluated while flying approaches to KMEM.

The Blended and Slant Range VCS methods were the two EFVS HUD concepts tested. The only imagery shown on the HUD in these two conditions was confined to the $20^{\circ} \mathrm{H} \mathrm{x} 15^{\circ} \mathrm{V}$ sensor window.

American Institute of Aeronautics and Astronautics 
All three CVS HUD concepts employed SVS imagery (full-time) outside the EFVS sensor window, but differed in how and when the SVS imagery was drawn within the sensor window. Two of the CVS concepts used the Blended EFVS imagery and differed only in whether SVS was drawn within the sensor window based on altitude (referred to as SVS/Timed Insertion of Blended) or not drawn within the sensor window at all (referred to as SVS/Blended). In the SVS/Timed Insertion of Blended CVS concept, SVS imagery was drawn within the sensor window when radar altitude was above $700 \mathrm{ft}$ above ground level (AGL) or EFVS imagery was drawn within it when under $500 \mathrm{ft}$ AGL. During the transition from $700 \mathrm{ft}$ to $500 \mathrm{ft}$ AGL, there was a gradual transition from $100 \%$ SVS imagery to $100 \%$ EFVS Blended imagery within the sensor window. In the SVS/Blended CVS concept, only sensor imagery is drawn within the sensor window. In the third CVS concept (referred to as SVS/Slant Range), SVS imagery was used as a third sensor input into the slant range concept and it is drawn within the sensor window at ranges beyond the $2 \mathrm{~nm}$ range of the MMWR sensor.

In Figure 2, two of the CVS HUD Concepts are shown - SVS/Blended (left) and SVS/Slant Range (right).
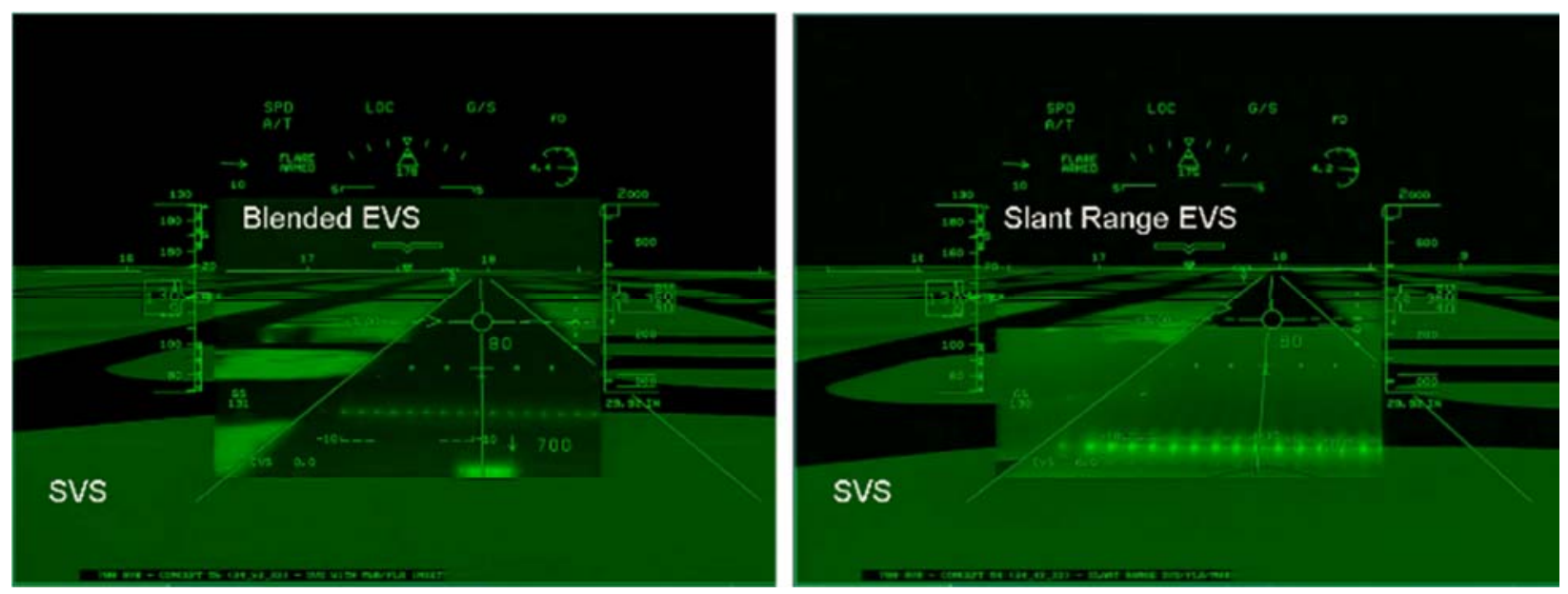

Figure 2. Two CVS HUD Formats - SVS/Blended EFVS (left) and SVS/Slant Range EFVS (right).

During the HUD experimental runs, a synthetic vision PFD with an identical 20 deg H by 15 deg V sensor window was displayed to both the PF and PM. The PFD was used as an alternate display for EVS as per RTCA DO-341 (Figure 3). The head-down primary and navigation display format was invariant.

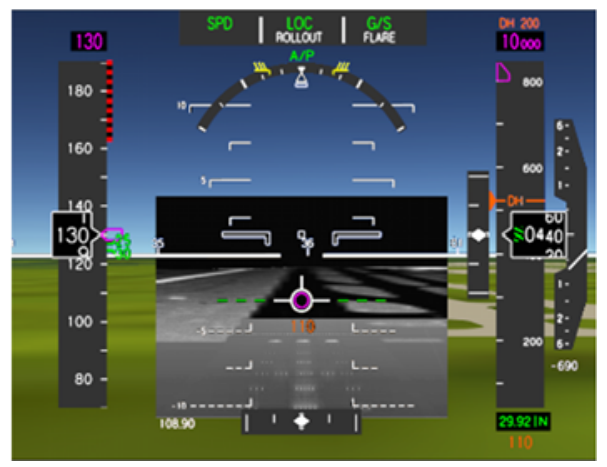

Figure 3. Primary Flight Display with sensor inset window.

2. Visibility Level

Four OTW visibility levels, $300 \mathrm{ft}, 700 \mathrm{ft}, 1000 \mathrm{ft}$, and $1800 \mathrm{ft}$, RVR, were tested in combination with the HUD VS concepts.

3. Airport Lighting

Two airport lighting configurations were tested in combination with the HUD VS concepts:

- Standard Category I/Type I operations runway, MALSR ALS without TDZ/CL lights

- Standard Category III/Type III operations runway, ALSF-2 ALS with TDZ/CL lights 


\section{Evaluation Task}

During data collection, crews flew both nominal and off-nominal (e.g., PF HUD failure) instrument approaches and departures with the different HUD VS concepts. Due to space limitations, only the nominal approach runs flown will be discussed in this paper.

The PF hand-flew the IAPs from the left seat with the autothrottles engaged. Each approach started level at 2000 $\mathrm{ft}$ AGL, approximately $8 \mathrm{~nm}$ from the runway threshold, with 180 knots indicated airspeed, landing gear up and flaps at $20 \mathrm{deg}$. The PF maintained level flight at $2000 \mathrm{ft}$ until intercepting the ILS glide path. At their discretion, the crews configured the ownship for landing (landing gear down, flaps $30 \mathrm{deg}$ ) with a final approach speed of 130 knots. Simulated ATC provided clearances and taxi instructions for the ownship and other traffic in the airport environment. The run was terminated once the PF completed the landing, roll-out, and turn-off or upon go-around initiation.

The weather consisted of cross winds (up to 15 knots), light turbulence (root-mean-square of $2 \mathrm{ft} / \mathrm{sec}$ ), and varying visibility levels.

The PFs were instructed to fly the aircraft as if there were passengers aboard, track the approach path, and land within the touchdown zone (first $3000 \mathrm{ft}$ of the runway) as close to the centerline as possible with an acceptable sink rate (less than $10 \mathrm{ft} / \mathrm{sec}$ ). After landing, they were to maintain the centerline and exit at the expected taxiway at a speed of 5 to 15 knots at the 90 degree exits or 30 knots at the high-speed exits. They were also instructed to initiate a goaround if the approach became unstable or if there were any safety concerns.

\section{E. Crew Procedures}

The PF hand-flew the approach using the HUD as the primary flight reference. The PM monitored using the available HUD and HDD information and the OTW scene and assisted the PF as appropriate and necessary. There was no transfer of control from the PF to PM (or vice versa) during normal operations. The crew procedures were standardized and trained.

The procedures for the Conventional HUD (i.e., symbology only; no SVS or EFVS imagery) followed normal crew instrument approach procedures. Training emphasized that the crews follow $\S 91.175$ procedures that the required visual references to continue the approach below the published DA/DH and for landing must be distinctly visible and identifiable by the pilot using natural vision.

The EFVS procedures were built around common practice in current EFVS operations and FAA requirements (14 CFR $\S 91.175$ (1)) but extended to emphasize that to descend below the DA/DH and to descend below $100 \mathrm{ft}$ height above the TDZE depended upon the PF being able to recognize and identify the required visual references, using EFVS. The PF was instructed to continue the landing if the required visual references were seen in the EV imagery on the HUD and if he/she determined that a safe landing could be performed. Otherwise, a missed approach should be executed.

\section{F. Experiment Matrix}

Nominally, 19 training runs and 28 experimental runs were completed by each crew. The primary approach experiment matrix consisted of combinations (but not a full-factorial) of HUD VS Concept (Conventional-No imagery, FLIR EFVS, Blended EFVS, Slant Range EFVS, SVS/Blended CVS, SVS/Timed Insertion of Blended CVS, or SVS/Slant Range CVS), airport lighting (Cat I or Cat III), and runway visibility range (300 ft, $700 \mathrm{ft}, 1000 \mathrm{ft}$ or $1800 \mathrm{ft}$ ) as shown in Table 1. There were also 3 off-nominal approaches and 7 departures completed by each crew, but only the nominal approach runs are considered within this paper.

Table 1. Nominal Approach Experiment Matrix

\begin{tabular}{|c|c|c|c|c|c|c|c|c|}
\hline & & & & & Dua & JD Concepts & & \\
\hline $\begin{array}{l}\text { Airport } \\
\text { Lighting }\end{array}$ & $\begin{array}{c}\text { Visibility } \\
\text { Level } \\
\text { (ft) }\end{array}$ & $\begin{array}{l}\text { Conv. } \\
\text { HUD }\end{array}$ & $\begin{array}{l}\text { FLIR } \\
\text { EFVS }\end{array}$ & $\begin{array}{l}\text { Blended } \\
\text { EFVS }\end{array}$ & $\begin{array}{c}\text { Slant } \\
\text { Range } \\
\text { EFVS }\end{array}$ & $\begin{array}{c}\text { SVS/Blended } \\
\text { EFVS }\end{array}$ & $\begin{array}{l}\text { SVS/Timed } \\
\text { Insert Blended } \\
\text { EFVS }\end{array}$ & $\begin{array}{c}\text { SVS/Slant } \\
\text { Range } \\
\text { EFVS }\end{array}$ \\
\hline \multirow{4}{*}{ Category I } & 1800 & $\mathrm{x}$ & & & & & & \\
\hline & 1000 & & $\mathrm{x}$ & $\mathrm{x}$ & $\mathrm{x}$ & & & \\
\hline & 700 & & & $\mathrm{x}$ & $\mathrm{x}$ & $\mathrm{x}$ & $\mathrm{x}$ & $\mathrm{x}$ \\
\hline & 300 & & & $\mathrm{x}$ & $\mathrm{x}$ & $\mathrm{x}$ & $\mathrm{x}$ & $\mathrm{x}$ \\
\hline \multirow{2}{*}{ Category III } & 700 & & & $\mathrm{x}$ & $\mathrm{x}$ & & & \\
\hline & 300 & & & $\mathrm{x}$ & $\mathrm{x}$ & & & \\
\hline
\end{tabular}


To enable the crews to more easily make comparisons on the HUD VS concepts, the run orders were blocked by visibility level $(300,700,1000$, or $1800 \mathrm{ft}$ ) and operation (approach or departure). The order of display concepts evaluated within each visibility/operation block were randomized. The order of the visibility/operation blocks were also randomized among the 12 crew run orders to minimize learning/training effects. In total, 336 runs (28 runs x 12 crews) were conducted for this experiment.

\section{G. Measures}

During each approach and landing run, path error, pilot control inputs, and touchdown performance (sink rate and speed at touchdown, longitudinal and lateral landing distance) were measured for analysis.

After each run, pilots completed the Air Force Flight Test Center (AFFTC) Workload Estimate Scale ${ }^{21}$ and Likerttype questions on the usability of the HUD VS concept used for the aircraft operation (approach or departure) they had just conducted. After data collection was completed, crews provided rank orders on which HUD VS concept (Blended, Slant Range, SVS/Blended, SVS/Timed Insertion of Blended, SVS/Slant Range) they preferred to fly with in visibilities as low as $300 \mathrm{ft}$ RVR. Crews were also administered the Situation Awareness - Subjective Workload Dominance (SA-SWORD) ${ }^{22}$ technique to evaluate HUD VS formats tested. Through a semi-structured interview, the pilots also responded to a post-test questionnaire to elicit comments on operational benefits/detriments observed with regard to 1) the blended method, 2) the slant range method, and 3) adding SVS to the EFVS imagery.

\section{H. Test Conduct}

The subjects were given a 1.5 hour briefing describing the experiment, HUD EFVS and CVS concepts, FLIR and MMWR sensor characteristics, crew procedures, and evaluation tasks. The test purpose was described to the test subjects as "evaluating various EFVS display concepts flown with varying weather/visibility conditions on instrument approach and departure procedures."

After the briefing, a 2.5 hour training session in the RFD was conducted to familiarize the subjects with the aircraft handling qualities; display symbologies; FLIR, MMWR, and SVS imagery differences; pilot procedures; and controls. In particular, in-simulator training highlighted the crew procedures for EFVS and landing performance. The training emphasized that they must always remain safe and if they felt unsafe conditions exist, the necessary precautions, including a go-around, should be executed immediately.

Since none of the pilots were familiar with the handling characteristics of the RFD simulator (a sidestick-equipped B-757), each PF was trained to an acceptable standard of performance.

Table 2. Touchdown Performance Scorecard

\begin{tabular}{|c|c|c|c|}
\hline Performance Value & Desired & Adequate & Not Adequate \\
\hline Lateral Distance from Centerline & Within $+/-27 \mathrm{ft}$ & $\begin{array}{c}\text { Between }+27 \text { and }+58 \mathrm{ft} \text { or } \\
\text { Between }-27 \text { and }-58 \mathrm{ft}\end{array}$ & $>+/-58 \mathrm{ft}$ \\
\hline Longitudinal Distance from Threshold & Between 750 to $2250 \mathrm{ft}$ & $\begin{array}{c}\text { Between } 200 \& 750 \mathrm{ft} \text { or } \\
\text { Between } 2250 \& 2700 \mathrm{ft}\end{array}$ & $<200 \mathrm{or}>2700 \mathrm{ft}$ \\
\hline Sink rate & Between 0 to $6 \mathrm{ft} / \mathrm{sec}$ & Between 6 to $10 \mathrm{ft} / \mathrm{sec}$ & $>10 \mathrm{ft} / \mathrm{sec}$ \\
\hline Airspeed (kts) & Between $\mathrm{V}_{\text {ref }}-5$ to $\mathrm{V}_{\text {ref }}+5$ & Between $\mathrm{V}_{\text {ref }}-5$ to $\mathrm{V}_{\text {ref- }}-15$ & $\begin{array}{c}<\mathrm{V}_{\text {ref- }}-15 \mathrm{or} \\
>\mathrm{V}_{\text {ref }}+5\end{array}$ \\
\hline
\end{tabular}

Note: Vref +5 is the approach speed

In Table 2, touchdown performance criteria are shown. These criteria were developed by using existing FAA $\mathrm{AC} 120-28 \mathrm{D}^{23}$ and JAR AWO ${ }^{24}$ performance-based "auto-land" standards for touchdown (T/D) longitudinal position, lateral position from centerline, and sink rate.

After each training run, a landing performance "scorecard" against these criteria was displayed for feedback. The pilots were asked to meet the desired performance criteria. Training concluded once the pilots demonstrated repeatable desired landing performance, albeit with an occasional adequate performance score.

Data collection lasted approximately eight hours and was followed by debriefings which included a final questionnaire. The entire session including lunch and breaks lasted approximately two days.

\section{Results}

A repeated measures design was used for this experiment in which multiple measurements (dependent variables) were made on the same subject (pilot) under different experimental conditions (factors). Linear Mixed Models (LMMs) - statistical models for continuous dependent measures in which the residuals are normally distributed but may not be independent or have constant (homogeneous) variance - were applied in the analysis. The within-subject

American Institute of Aeronautics and Astronautics 
fixed factors for this experiment were HUD display concept, visibility level, and airport lighting configuration. The random factor was crew.

By-subject variance due to individual differences was accounted for by using a Random Intercept Model in the LMM analyses. Unless otherwise specified, all LMMs: 1) employed the Identity (constant variance and independent residuals) covariance structure for the residuals, 2) were estimated with restricted maximum likelihood, and 3) met the assumptions of normality and constant variance for the residuals and for the random effects.

The dependent variables evaluated for approach performance in the instrument segment (from $1000 \mathrm{ft}$ AGL to the DH of $200 \mathrm{ft} \mathrm{AGL)} \mathrm{were} \mathrm{root-mean-square} \mathrm{(RMS)} \mathrm{localizer} \mathrm{error} \mathrm{(in} \mathrm{dots),} \mathrm{RMS} \mathrm{glideslope} \mathrm{error} \mathrm{(in} \mathrm{dots),} \mathrm{and} \mathrm{RMS}$ sink rate deviation (in $\mathrm{ft} / \mathrm{min}$ ) where this value is difference or deviation from the sink rate required to perfectly track the glideslope in the given wind conditions.

The dependent variables for approach performance in the visual segment were lateral deviation from centerline (in $\mathrm{ft}$ ) and sink rate (in ft/min) at two altitudes - $100 \mathrm{ft}$ height above threshold elevation (HAT) and $50 \mathrm{ft}$ HAT.

The dependent variables evaluated for landing performance were touchdown longitudinal position (in $\mathrm{ft}$ ), touchdown lateral position (in $\mathrm{ft}$ ), and touchdown sink rate (in $\mathrm{ft} / \mathrm{sec}$ ). Touchdown statistics were used to evaluate how effectively the pilots could land with the different HUD VS concepts. In addition, the number of landings and the number of go-arounds for the various combinations of fixed factors are provided. These data were provided in tabular form. Note that for touchdown lateral position data in these tables, the "min" value equates to the maximum deviation to the left of centerline and the "max" value equates to the maximum deviation to the right of centerline.

Post-run workload was assessed using the AFFTC Workload Estimate technique which provided independent, self-reported PF and PM workload ratings as crews conducted approaches using the different HUD VS concepts. Posttest Situation Awareness (SA) was assessed using the SA-SWORD paired-comparison technique which provided relative SA ratings across the five VS concepts (EFVS and CVS) presented on the HUD.

To test for EFVS imagery effects, LMM analyses were conducted on the approach and landing performance measures for the following 5 operational concepts: Conventional HUD flown in 1800 RVR, Blended EFVS (flown in either 300 or 700 RVR), and Slant Range EFVS (flown in either 300 or 700 RVR). The operational baseline for these comparisons was the conventional HUD (symbology only, no EV) flown in 1800 RVR which is the lowest visibility authorized to manually fly a HUD for Cat 1 approach with $200 \mathrm{ft} \mathrm{DH}$. This baseline condition creates the direct comparison of "visual segment" performance (from DA/DH to touchdown and roll-out) in the lowest visibility (1800 $\mathrm{ft}$ RVR) allowable using natural vision under today's regulations against an EFVS "visual segment". The Cat I airport lighting (i.e., MALSR ALS with no TDZ/CL lights) was held fixed for these analyses. To test for visibility and lighting effects, LMM analyses were conducted on the approach and landing performance measures for the fixed factors of EFVS HUD concept (Blended or Slant Range), Airport Lighting (Cat I or III), and visibility level (300 or $700 \mathrm{ft}$ ) and their second order interactions. To test for SV imagery effects, LMM analyses were conducted on the approach and landing performance measures for the fixed factors of HUD VS concept (Blended, Slant Range, SVS/Blended, SVS/Timed Insert of Blended, or SVS/Slant Range) and visibility level (300 or $700 \mathrm{ft})$ and their interaction. The Cat I airport lighting was held fixed for these analyses. Additionally, marginal model (MM) analyses using a Diagonal covariance structure for the residuals were conducted on the PF and PM SA-SWORD ratings.

\section{A. Flight Performance - EFVS to touchdown}

The effects of using dual sensor (FLIR and MMWR) EFVS imagery on a HUD while flying an IAP to runways with Cat I lighting on approach and landing performance were assessed. The operational baseline for these comparisons was the conventional HUD (symbology only, no EV) flown in 1800 RVR which is the lowest visibility authorized to manually fly a HUD for Cat 1 approach with $200 \mathrm{ft} \mathrm{DH}$. This configuration was used for comparative analysis in three primary performance aspects: 1) the flight technical error to the DH; 2) the ability of the pilot to fly below the DA/DH to the runway; and, 3) the pilot's ability to safely land in the touchdown zone, with an acceptable sink rate. For the baseline condition, below the DA/DH, the pilot's primary reference for maneuvering the aircraft was the OTW visual cues (i.e., natural vision). In the case of an EFVS, the pilot's primary reference for maneuvering the aircraft was the enhanced flight vision cues. For a HUD EFVS configuration to be considered for operational approval to use EFVS in lieu of natural vision to descend below the DA/DH and land and roll-out, equivalent performance to an approach where natural vision is relied on below the DA/DH must be demonstrated.

Of the 60 HUD approaches considered in these analyses, all resulted in a safe landing. There were no go-arounds performed.

\section{Approach Performance}

During the instrument segment of the approach, there were no significant $(p>0.05)$ differences for HUD operational concept (Conventional/1800 RVR; Blended/700 RVR; Slant Range/700 RVR, Blended/300RVR, Slant

American Institute of Aeronautics and Astronautics 
Range/300 RVR) for RMS glide slope deviation (mean, $M=0.062$ dots), RMS localizer deviation ( $\mathrm{M}=0.025$ dots), or RMS sink rate deviation (from a nominal 3-degree glideslope value) $(\mathrm{M}=55 \mathrm{ft} / \mathrm{min})$.

The data show that all five HUD operational concepts were well within the lateral confines of the $150 \mathrm{ft}$ wide runway at $100 \mathrm{ft} \operatorname{HAT}(\mathrm{M}=6 \mathrm{ft}$ lateral deviation from centerline, maximum deviation $=25 \mathrm{ft})$ with an acceptable sink rate $(\mathrm{M}=-667 \mathrm{ft} / \mathrm{min}$, standard deviation, $\mathrm{SD}=54 \mathrm{ft} / \mathrm{min})$ and also, at $50 \mathrm{ft}$ HAT $(\mathrm{M}=5 \mathrm{ft}$ lateral deviation from centerline, maximum deviation $=21 \mathrm{ft})$ with an acceptable sink rate $(\mathrm{M}=-550 \mathrm{ft} / \mathrm{min}, \mathrm{SD}=129 \mathrm{ft} / \mathrm{min})$.

\section{Touchdown Performance}

There were no significant ( $>0.05)$ T/D longitudinal position $(\mathrm{M}=1044 \mathrm{ft})$ or $\mathrm{T} / \mathrm{D}$ sink rate $(\mathrm{M}=4.5 \mathrm{ft} / \mathrm{sec})$ differences for HUD operational concept. A LMM analysis revealed significant differences in absolute value of lateral distance from centerline for HUD operational concept $(\mathrm{F}(4,44)=3.444, \mathrm{p}=0.016)$. Operationally, however, these lateral path differences were irrelevant as the average deviation from centerline was $5 \mathrm{ft}$.

\section{Crew Workload}

Independent analyses revealed no significant ( $\mathrm{p}>0.05)$ PF or PM AFFTC workload rating differences for HUD operational concept. The overall mean PF workload rating was 3.2 indicating workload was moderate and easily managed. The overall mean PM workload rating was 2.7 indicating workload was light to moderate with minimal demand.

\section{Flight Performance Discussion}

Comparable flight performance without any workload penalty was observed between the baseline operational condition (conventional HUD) and the EFVS concepts as pilot flew approaches to runways with Cat I lighting. No go arounds were performed while using a Conventional HUD in $1800 \mathrm{ft}$ visibility or while using an EFVS HUD in visibilities as low as $300 \mathrm{ft}$. Based solely on the EV imagery, crews were able to identify the required visual landing references to continue the approach to landing. All landings were within autoland touchdown tolerances.

\section{B. Flight Performance -Visibility and Lighting Effects on EFVS Concept}

The effects of using dual sensor EFVS concepts (Blended, Slant Range) during extremely low visibility (300 RVR, 700 RVR) approaches to runways with Type I vs. Type III lighting on approach and landing performance were assessed. Of the 96 EFVS HUD approaches considered in these analyses, all resulted in a safe landing. There were no go-arounds performed (see Table 3).

\section{Approach Performance}

Separate LMM analyses revealed significant differences in the interaction between EFVS concept and visibility level for RMS glide slope deviation $(\mathrm{F}(1,78)=5.61, \mathrm{p}=0.02)$ and $\mathrm{RMS}$ sink rate deviation $(\mathrm{F}(1,78)=10.41, \mathrm{p}=0.002)$ during the instrument segment of the approach (from $1000 \mathrm{ft}$ to $200 \mathrm{ft}$ AGL). Operationally, these differences were inconsequential as crews had excellent tracking of the glide slope $(\mathrm{M}=0.06$ dots, $\mathrm{SD}=0.04$ dots) and in sink rate maintenance ( sink rate error, $\mathrm{M}=54 \mathrm{ft} / \mathrm{min}, \mathrm{SD}=13 \mathrm{ft} / \mathrm{min}$ ) for each $\mathrm{EFVS}$ concept/visibility level combination flown. There were no significant differences $(\mathrm{p}>0.05)$ in the main factors or remaining second order interactions for RMS glide slope deviation or RMS sink rate deviation.

An LMM analysis revealed significant localizer tracking differences during the instrument segment of the approach for EFVS concept $(\mathrm{F}(1,78)=4.27, \mathrm{p}=0.04)$ and visibility level $(\mathrm{F}(1,78)=6.90, \mathrm{p}=0.01)$. Crews flew more precise laterally with the Blended ( $\mathrm{M}=0.022$ dots) concept than with the Slant Range ( $\mathrm{M}=0.026$ dots) concept and when the visibility was $300 \mathrm{ft}(\mathrm{M}=0.022$ dots $)$ OTW compared to $700 \mathrm{ft}(\mathrm{M}=0.027 \mathrm{dots})$. Operationally, these lateral tracking differences are inconsequential. There were no significant differences $(p>0.05)$ in airport lighting or any of the second order interactions for this measure.

The data show that all EFVS concepts, regardless of visibility level $(300,700 \mathrm{ft})$ or airport lighting (Cat I, Cat III), were well within the lateral confines of the runway ( $\pm 75 \mathrm{ft}$ of centerline) at $100 \mathrm{ft}$ HAT with an acceptable sink rate $(\mathrm{M}=-675 \mathrm{ft} / \mathrm{min}, \mathrm{SD}=53 \mathrm{ft} / \mathrm{min})$ and also, at $50 \mathrm{ft}$ HAT with an acceptable sink rate $(\mathrm{M}=-567 \mathrm{ft} / \mathrm{min}, \mathrm{SD}=101 \mathrm{ft} / \mathrm{min})$ (see Figure 4, where the boxplot's central mark is the median, the edges of the box are the 25th and 75th percentiles, the whiskers extend to 1.5 times the height of the box or, if no values in that range, to the minimum and maximum values, and outliers are plotted individually. Circles are outliers that represent values between 1.5 to 3 times the height of the box. Asterisks are extreme outliers that represent values more than three times the height of the box.).

American Institute of Aeronautics and Astronautics 


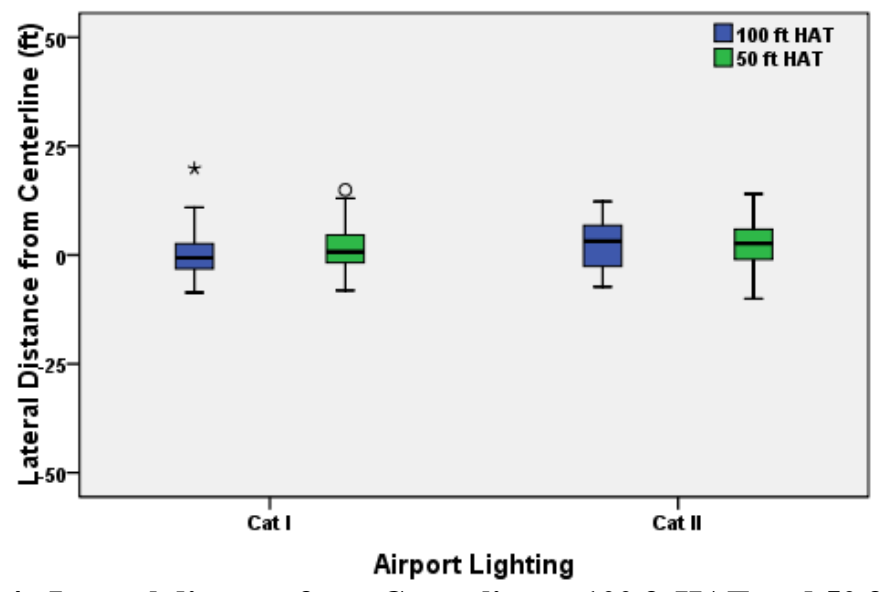

Figure 4. Lateral distance from Centerline at $100 \mathrm{ft}$ HAT and $50 \mathrm{ft} \mathrm{HAT}$.

\section{Touchdown Performance}

In Table 3, the touchdown (T/D) statistics (mean, standard deviation, minimum value, and maximum value) are shown, broken out by visibility level and airport lighting configuration, for the HUD EFVS concepts flown.

Table 3. Touchdown Statistics for EFVS Concepts by Visibility Level and Airport Lighting

\begin{tabular}{|c|c|c|c|c|c|c|c|c|c|}
\hline & \multicolumn{4}{|c|}{$300 \mathrm{ft}$ RVR } & \multicolumn{4}{|c|}{$700 \mathrm{ft}$ RVR } \\
\hline & & \multicolumn{2}{|c|}{ Blended } & \multicolumn{2}{|c|}{ Slant Range } & \multicolumn{2}{|c|}{ Blended } & \multicolumn{2}{|c|}{ Slant Range } \\
\hline & & $\begin{array}{c}\text { Cat I } \\
\text { airport } \\
\text { Lighting }\end{array}$ & $\begin{array}{l}\text { Cat III } \\
\text { airport } \\
\text { lighting }\end{array}$ & $\begin{array}{c}\text { Cat I } \\
\text { airport } \\
\text { Lighting }\end{array}$ & $\begin{array}{l}\text { Cat III } \\
\text { airport } \\
\text { lighting }\end{array}$ & $\begin{array}{c}\text { Cat I } \\
\text { airport } \\
\text { Lighting }\end{array}$ & $\begin{array}{l}\text { Cat III } \\
\text { airport } \\
\text { lighting }\end{array}$ & $\begin{array}{c}\text { Cat I } \\
\text { airport } \\
\text { Lighting }\end{array}$ & $\begin{array}{l}\text { Cat III } \\
\text { airport } \\
\text { lighting }\end{array}$ \\
\hline \multicolumn{2}{|c|}{ \# TOGA \# Runs } & $0 / 12$ & $0 / 12$ & $0 / 12$ & $0 / 12$ & $0 / 12$ & $0 / 12$ & $0 / 12$ & $0 / 12$ \\
\hline \multirow{5}{*}{ 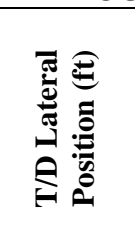 } & Mean & -0.1 & -0.7 & -0.01 & 0.9 & 5.6 & 8.7 & 2.6 & 10.6 \\
\hline & Std Dev & 3.9 & 5.9 & 4.9 & 4.8 & 5.2 & 6.6 & 4.3 & 4.0 \\
\hline & Min & -9.0 & -10.0 & -10.1 & -6.4 & -3.8 & -1.1 & -4.8 & 1.1 \\
\hline & Max & 6.1 & 11.6 & 7.3 & 7.5 & 13.7 & 23.2 & 9.3 & 18.2 \\
\hline & Rating & Desired & Desired & Desired & Desired & Desired & Desired & Desired & Desired \\
\hline \multirow{5}{*}{ 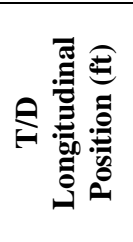 } & Mean & 1182.5 & 1252.0 & 1047.8 & 1261.9 & 1066.0 & 1284.0 & 1015.0 & 1120.5 \\
\hline & Std Dev & 348.9 & 358.7 & 207.4 & 304.9 & 366.3 & 426.5 & 419.2 & 173.3 \\
\hline & Min & 812.4 & 847.9 & 744.7 & 829.1 & 666.0 & 824.3 & 692.6 & 828.2 \\
\hline & Max & 1681.9 & 2203.2 & 1464.6 & 1818.7 & 1814.1 & 2009.0 & 1875.8 & 1488.7 \\
\hline & Rating & Desired & Desired & Desired & Desired & Desired & Desired & Desired & Desired \\
\hline \multirow{5}{*}{ 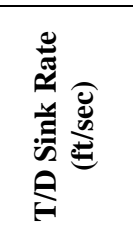 } & Mean & -4.0 & -5.3 & -4.6 & -5.0 & -4.7 & -5.3 & -4.0 & -4.9 \\
\hline & Std Dev & 1.7 & 2.1 & 1.0 & 2.2 & 1.6 & 1.3 & 1.5 & 2.3 \\
\hline & Min & -7.5 & -8.0 & -6.6 & -9.4 & -7.2 & -7.3 & -7.2 & -9.8 \\
\hline & Max & -1.7 & -1.6 & -3.4 & -2.1 & -1.9 & -3.1 & -1.8 & -1.9 \\
\hline & Rating & Desired & Desired & Desired & Desired & Desired & Desired & Desired & Desired \\
\hline
\end{tabular}

All T/D measures (lateral position, longitudinal position and sink rate) for both the Blended and Slant Range HUD EFVS concepts were on average within the "Desired" landing performance criteria (Table 2), regardless of visibility level (300 or $700 \mathrm{ft}$ ) or airport lighting configuration (Cat I or Cat III).

All dual sensor EFVS approaches resulted in landings (i.e., no go-arounds), regardless of visibility level (300 or $700 \mathrm{ft}$ ) or airport lighting configuration (Cat I or Cat III) in which it was flown.

Separate LMM analyses revealed significant airport lighting differences for the T/D measures of distance from threshold $(\mathrm{F}(1,78)=7.30, \mathrm{p}=0.008)$ and sink rate $\mathrm{F}(1,78)=5.65, \mathrm{p}=0.02)$. The approaches made using Cat $\mathrm{I}$ lighting $(\mathrm{M}=1074 \mathrm{ft})$ were closer to the $1000 \mathrm{ft}$ aim point than the approaches using Cat III lighting $(\mathrm{M}=1225 \mathrm{ft})$ and the 300 $\mathrm{ft}$ visibility landings $(\mathrm{M}=-4.6 \mathrm{ft} / \mathrm{sec})$ were made less firmly than the $700 \mathrm{ft}$ visibility landings $(\mathrm{M}=-5.3 \mathrm{ft} / \mathrm{sec})$. A LMM

American Institute of Aeronautics and Astronautics 
analysis revealed significant differences in absolute value of lateral distance from centerline for the main factors, visibility level $(\mathrm{F}(1,78)=23.32, \mathrm{p}<0.0001)$ and airport lighting $(\mathrm{F}(1,78)=12.92, \mathrm{p}=0.001)$, and their interaction $(\mathrm{F}(1,78)=5.33, \mathrm{p}=0.024)$. Operationally, however, these lateral path differences were irrelevant as the average deviation from centerline was $6 \mathrm{ft}$.

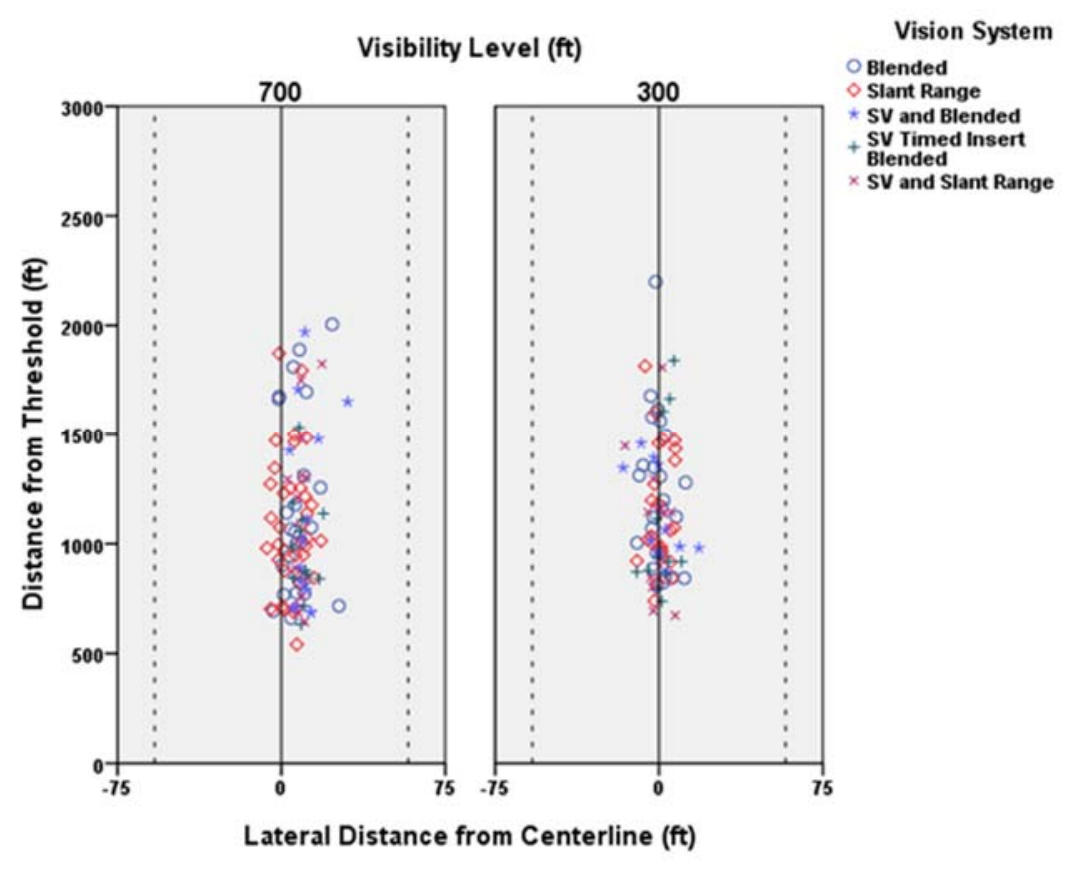

Figure 5. Landings by HUD Vision System Concept and Visibility Level

Visual inspection of the data in Figure 5 showed that all HUD concepts, regardless of vision system type (Blended, SVS/Timed Insert of Blended, SVS/Blended, Slant Range, or SVS/Slant Range) or visibility level (300 or $700 \mathrm{ft}$ ), were within the JAR lateral and longitudinal touchdown criteria footprint (laterally within $58 \mathrm{ft}$ of centerline and longitudinally between 200 and $2700 \mathrm{ft}$ from the threshold).

3. Crew Workload

Independent analyses revealed no significant ( $\mathrm{p}>0.05$ ) PF or PM AFFTC workload rating differences for the main factors (VS concept, visibility level, or airport lighting) or their interactions. The overall mean PF workload rating was 3.1 indicating workload was moderate and easily managed. The overall mean PM workload rating was 2.6 indicating workload was light to moderate with minimal demand.

\section{Flight Performance Discussion}

Regardless of being hand-flown in visibilities as low as 300 RVR, each dual sensor EFVS concept flown enabled crews to achieve excellent approach and landing performance without any penalty in crew workload. No go arounds were performed for any combination of EFVS concept (Blended, Slant Range), visibility level (300 ft, $700 \mathrm{ft}$ ), or airport lighting configuration (with our without TDZ/CL lights) tested. All landings were made within autoland touchdown tolerances. Post-test, pilots commented that either method (Blended or Slant Range) of combining FLIR and MMWR imagery was acceptable for conducting approaches in low visibility conditions.

\section{Flight Performance -Synthetic Vision and Visibility Effects on EFVS Concepts}

The effects of adding SVS to the dual sensor EFVS concepts (Blended, Slant Range) during extremely low visibility (300 RVR, 700 RVR) approaches to runways with Type I lighting on approach and landing performance were assessed. Of the $120 \mathrm{EFVS/CVS} \mathrm{HUD} \mathrm{approaches} \mathrm{considered} \mathrm{in} \mathrm{these} \mathrm{analyses,} \mathrm{one} \mathrm{go-around} \mathrm{was} \mathrm{safely}$ performed while flying the SVS/Blended CVS concept to a runway without TDZ/CL lights in the $300 \mathrm{ft}$ OTW visibility level. Review of run notes revealed that the PF said "something flickered and I did a go around. Then right after that I had everything I needed [to continue approach]." The video file was unavailable for review to see what may have "flickered" in the scene that triggered the PF to initiate a go-around.

American Institute of Aeronautics and Astronautics 


\section{Approach Performance}

During the instrument segment of the approach, there were no significant $(\mathrm{p}>0.05)$ differences for the main factors of VS concept (Blended, SVS/Blended, SVS/Timed Insert of Blended, Slant Range, SVS/Slant Range) and visibility level $(300,700 \mathrm{ft})$ or their interaction for RMS glide slope deviation (M=0.062 dots), RMS localizer deviation $(\mathrm{M}=0.025$ dots$)$, or RMS sink rate deviation $(\mathrm{M}=55 \mathrm{ft} / \mathrm{min})$.

The data show that all VS concepts regardless of visibility level $(300,700 \mathrm{ft})$ were well within the lateral confines of the runway ( $\pm 75 \mathrm{ft}$ of centerline) at $100 \mathrm{ft}$ HAT with an acceptable sink rate $(\mathrm{M}=-672 \mathrm{ft} / \mathrm{min}, \mathrm{SD}=53 \mathrm{ft} / \mathrm{min})$ and also, at $50 \mathrm{ft}$ HAT with an acceptable sink rate $(\mathrm{M}=-541 \mathrm{ft} / \mathrm{min}, \mathrm{SD}=101 \mathrm{ft} / \mathrm{min}$ ) (see Figure 6).

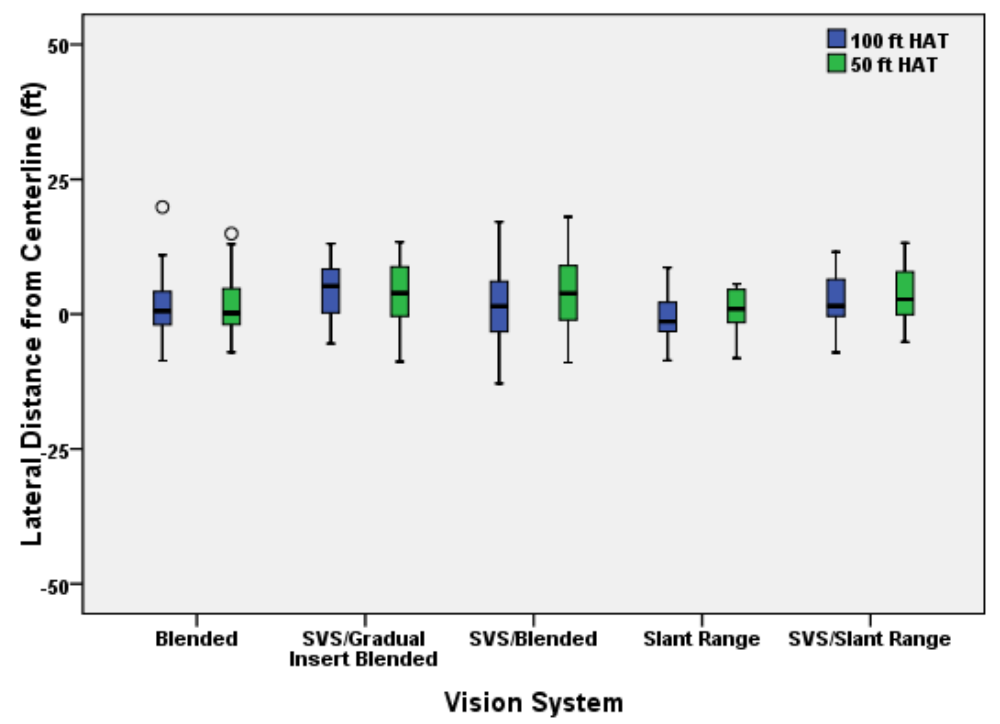

Figure 6. Lateral Distance from Centerline at $100 \mathrm{ft}$ HAT and $50 \mathrm{ft} \mathrm{HAT}$.

\section{Touchdown Performance}

Separate LMM analyses revealed no significant $(\mathrm{p}>0.05)$ differences for the main factors of VS concept and visibility level $(300,700 \mathrm{ft})$ or their interaction for the touchdown measures of distance from threshold $(\mathrm{M}=1087 \mathrm{ft})$ and sink rate $(\mathrm{M}=-4.4 \mathrm{ft} / \mathrm{sec})$. There were significant lateral touchdown position differences for VS concept $(\mathrm{F}(4,98)=4.58, \mathrm{p}=0.002)$ and visibility level $(\mathrm{F}(4,98)=25.65, \mathrm{p}<0.0001)$; however, these differences were operationally irrelevant as all means were within $8 \mathrm{ft}$ of the centerline.

As mentioned previously, all HUD concepts flown in motion, regardless of vision system type (Blended, SVS/Timed Insert of Blended, SVS/Blended, Slant Range, or SVS/Slant Range) or visibility level (300 or $700 \mathrm{ft}$ ), were within the JAR lateral and longitudinal touchdown criteria footprint (laterally within $58 \mathrm{ft}$ of centerline and longitudinally between 200 and $2700 \mathrm{ft}$ from the threshold).

\section{Crew Workload}

PF AFFTC workload ratings were significantly different for OTW visibility level. Pilots reported a lower workload when flying with $700 \mathrm{ft}$ OTW visibility ( $M=2.9)$ compared to when flying with $300 \mathrm{ft}(\mathrm{M}=3.3)$, but these differences are operationally insignificant. An AFFTC rating of 3 indicates the PF had moderate activity which was easily managed with considerable spare time available. There were no significant PF workload rating differences for VS concept, airport lighting or second order interactions.

There were no significant ( $>0.05)$ PM AFFTC workload rating differences for the main factors or their interactions. The overall mean was reported to be 2.6 indicating PM workload was light to moderate and easily managed.

\section{Effects of Adding SVS to EFVS Concepts Discussion}

No workload or approach/landing performance differences were observed with the addition of synthetic vision imagery to the dual sensor EFVS concepts. Crews were able to repeatedly achieve excellent approach and landing performance with each of the HUD VS concepts hand-flown in extremely low visibility conditions to runways without TDZ/CL lighting. Even in these low visibility conditions to a Cat I runway, pilots reported that their workload was easily managed with spare time available to attend to other activities. Although no performance differences were observed in the data, pilot comments revealed that they preferred having SVS imagery with the EFVS concepts as it 
increased their HUD's FOV, provided improvements in SA, and eliminated the false horizon created by the rangelimited EFVS sensors.

\section{Situation Awareness Ratings}

Post-test SA was assessed using the SA-SWORD paired-comparison technique which provided relative SA ratings across the five VS concepts (EFVS and CVS) presented on the HUD. For these comparisons, SA was defined as "The pilot's awareness and understanding of all factors that will contribute to the safe flying of their aircraft under normal and non-normal conditions." The PF and PM independently completed the SA-SWORD technique for the five VS formats tested on the HUD.

Independent $\mathrm{MM}$ analyses revealed HUD VS concept was significant for PF SA-SWORD ratings $(\mathrm{F}(4,22.6)=10.660, \mathrm{p}<0.001)$ and PM SA-SWORD ratings $(\mathrm{F}(4,19.94)=27.942, \mathrm{p}<0.001)$. On average, the SVS with timed insertion of the Blended MMWR/FLIR sensor imagery was rated by both crew members as providing the most situation awareness of the five VS formats tested on the HUD. In fact, the three VS formats that used SVS in conjunction with the MMWR/FLIR sensor imagery were rated (on average) as providing more SA than the sensor imagery-only VS formats by both crew members.

Post-hoc tests (LSD using $\alpha=0.05$ ) showed 3 overlapping subsets for the PF SA-SWORD ratings 1) SVS/Timed Insert of Blended, SVS/Slant Range, SVS/Blended (highest SA); 2) SVS/Blended, Slant Range; and 3) Slant Range, Blended (lowest SA). Post-hoc tests (LSD using $\alpha=0.05$ ) showed 3 unique subsets for the PM SA-SWORD ratings 1 ) SVS timed insertion of Blended (highest SA); 2) SVS and Blended, SVS and Slant Range; and 3) Blended, Slant Range (lowest SA). Not surprisingly, pilots commented having the SV-drawn runway environment versus an opaque EV image on the HUD when the sensors could not penetrate the weather on the approach (greater than $2 \mathrm{nmi}$ from ownship) provided them greater SA. However once the EV sensors provided the pilots with the required landing visual references, having SVS on the HUD did not provide any improvements in SA in the landing task. Pilots commented that having SVS during taxi operations provided improvements in SA as they could anticipate and visualize turns better with the larger FOV provided by the SVS/EFVS imagery.

\section{E. Preferred Display Rankings}

The PF and PM were independently asked to rank order the five VS formats tested from most preferred display $($ rank $=1)$ to least preferred display (rank=5) for flying with in low-visibility crew operations. In Figure 6 , the inverse mean rankings for the PF and PM display concept preferences are shown. By using the inverse of the preference rankings, the most preferred display would have a value of 1 and the least preferred display would have a value of 0.2 (i.e., $1 / 5=0.2$ ).

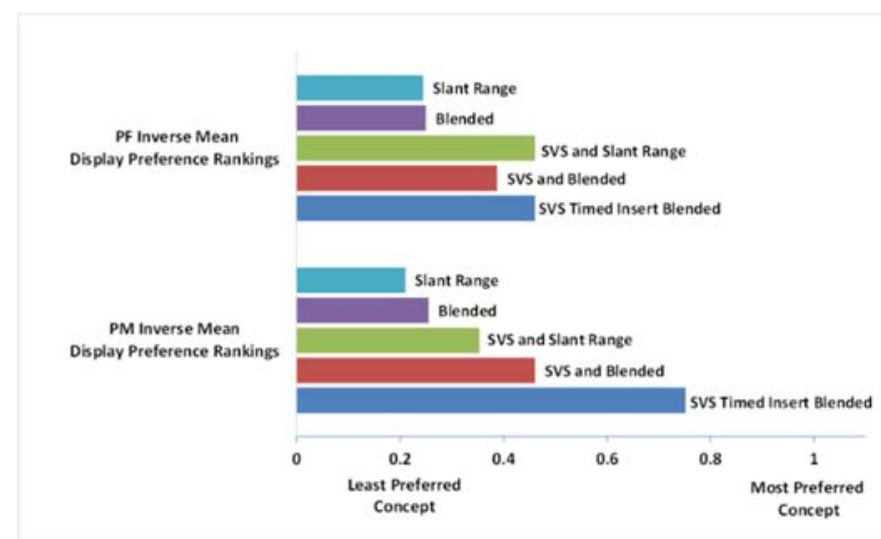

Figure 7. Crew Preferred HUD Display Concept in Low Visibility Operations.

The PF pilots ranked their low-visibility operations display concept preferences as follows: 1) SVS/Timed Insert Blended; SVS/Slant Range (most preferred, tied ranking), 2) SVS/Blended, 3) Blended, and 4) Slant Range (least preferred). Friedman's test statistic showed there were significant differences among the displays for the PF $\left(\chi^{2}(4)=17.933, p<0.001\right)$ preference rankings. Wilcoxon signed rank tests (tested at $\left.\alpha=0.025\right)$ indicate that there were no significant differences in rank order between the three EFVS formats that included SVS. However, PF preferences were significantly higher for SVS/Blended format versus Blended only format. The flying pilot preferred having SVS

American Institute of Aeronautics and Astronautics 
with the MMWR/FLIR EV sensors on the HUD during low visibility operations. Post-test comments revealed that they preferred having the synthetic vision runway environment versus an opaque EV image in the center of the HUD for initial approach operations and that having SVS was preferred during taxi operations as you could anticipate upcoming turns.

The PM pilots ranked their low-visibility operations display concept preferences as follows: 1) SVS/Timed Insert Blended (most preferred), 2) SVS/Blended, 3) SVS/Slant Range, 4) Blended, and 5) Slant Range (least preferred). Friedman's test statistic showed there were significant differences among the displays for the PM $\left(\chi^{2}(4)=35.533\right.$, $\mathrm{p}<0.0001$ ) preference rankings. Wilcoxon signed rank tests (tested at $\alpha=0.017$ ) indicated that there were no significant differences in rank order 1) between the two Blended Concepts that included SVS or 2) between the Blended and Slant Range VS formats. However, PM preferences were significantly better for SVS /Timed Insert Blended format than SVS/Slant Range format. The monitoring pilot preferred having SVS with the Blended MMWR/FLIR EV sensors on the HUD during low visibility operations. Post-test comments revealed the solid line demarcating the boundary between the FLIR and MMWR was somewhat distracting for a few of the monitoring pilots. However, both PF and PM pilots stated that all five VS formats were useable for terminal operations in visibilities as low as $300 \mathrm{RVR}$.

\section{Discussion}

The findings suggest making approaches in extremely low visibility conditions with a dual-sensor EFVS HUD appear feasible. Regardless of OTW visibility level or airport lighting configuration tested, all EFVS HUD approaches flown had comparable ILS tracking during the instrument segment and were within the lateral confines of the runway with acceptable sink rates during the visual segment of the approach. All approaches hand-flown with the EFVS HUD resulted in landings (i.e., no go arounds performed) that were within autoland tolerances. Subjective ratings, rankings, and comments revealed pilot preferences for having synthetic vision imagery with the dual-sensor EFVS HUD. There were no flight performance improvements with the addition of synthetic imagery on the EFVS HUD but the pilots felt it provided situation awareness improvements during initial approach operations and taxi operations.

The experiment fundamentally addressed three main questions:

- Can a vision system in $300 \mathrm{ft}$ RVR conditions provide equivalent levels of safety and performance to current-day Category 1 operations? The data suggests that the performance of the EFVS concepts in visibilities as low as $300 \mathrm{ft}$ RVR were no different than flying in $1800 \mathrm{ft} \mathrm{RVR}$ with a HUD without EFVS. (This condition is the current-day lowest Category I visibility permissible.) These data suggest that the simulated EFVS operation from a flight-deck standpoint enables equivalent visual operations.

- Were there differences in the types of EFVS for $300 \mathrm{ft} R V R$ operations? The data suggests that there were no operationally significant differences in performance between the EFVS concepts. In particular, the minimal FOV concepts were acceptable. However, the addition of SVS (creating the CVS concepts) showed significantly improved SA. SA has been associated with improved safety, thus, one could conjecture that the CVS concepts provide equivalent or better performance and safety. The CVS concepts provided additional benefit above and beyond the EFVS concepts by having larger FOV and creating visual momentum as the SVS information morphs to EFVS information in the blended and transitional concepts.

- What effect did the approach lighting system have? This issue is important since airport equipage in current-day Category III operations is an expensive proposition. The data suggests that there were no operationally significant differences as the lighting system varied. For the EFVS concepts tested, the approach lighting system and runway lighting configuration did not create any operationally significant differences. This result suggests that equivalent visual operations - i.e., operations as low as $300 \mathrm{ft}$ RVR enabled by the use of EFVS - can be employed to all runways with a minimum of runway infrastructure.

A few caveats should be considered when interpreting these results. There was no intentional misalignment with the FLIR or MMWR sensors in this simulation. It was assumed that sensor misalignments could be resolved by onboard processing. Additionally, the sensors were modeled with the same update rate. There was also no navigation solution error in the simulation so the SVS imagery lined up well with the OTW scene. Lastly, this research has not addressed to date the implications of these technologies on the airport operation and air traffic control. Obviously, how air traffic control and the airport can provide effective oversight, management, and control during EVO-type operations is critical to safety and operation efficiency. This work is needed.

American Institute of Aeronautics and Astronautics 


\section{Conclusions}

An experiment was conducted to investigate the use of vision system technologies, such as EFVS and SVS, as enabling technologies for future all-weather operations. The experimental objectives were to evaluate the operational feasibility, pilot workload and pilot acceptability of conducting straight-in instrument approaches with published vertical guidance to landing, touchdown, and rollout to a safe taxi speed in visibility as low as $300 \mathrm{ft}$ runway visual range by use of onboard vision system technologies on a HUD without need or reliance on natural vision. Crews evaluated two methods of combining dual sensor (millimeter wave radar and forward looking infrared) EFVS imagery on pilot-flying and pilot-monitoring HUDs as they made approaches to runways with and without touchdown zone and centerline lights. In addition, the impact of adding SV to the dual sensor EFVS imagery on crew flight performance, workload, and situation awareness during extremely low visibility approach and landing operations was assessed. Results indicate that all EFVS concepts flown resulted in excellent approach path tracking and touchdown performance without any workload penalty. Adding SV imagery to EFVS concepts provided situation awareness improvements but no discernible improvements in flight path maintenance.

Objective results indicate that making approaches with a dual sensor EFVS HUD, with or without synthetic vision, in visibilities as low as $300 \mathrm{RVR}$ appears feasible. Regardless of OTW visibility level or airport lighting configuration tested, all EFVS HUD approaches flown had comparable ILS tracking during the instrument segment, were within the lateral confines of the runway with acceptable sink rates during the visual segment of the approach, and were landed within the touchdown zone. All twelve crews universally decided that the EFVS provided all the visual cues required in the visual segment at or before the decision height to continue for a landing. Many crews had the required references as early as 500 feet. Most crews commented they wanted this system immediately and it was a significant improvement over current low visibility landing systems.

No operationally relevant path maintenance differences were found due to the absence or presence of SV imagery on the EFVS HUDs. Pilots preferred having SV with the EFVS imagery on the HUD for low visibility terminal operations.

FLIR sensor technology used in conjunction with MMWR on the HUD enabled successful approaches, without any workload penalty, in visibility as low as 300 RVR in this simulation experiment. Future research should include sensor characteristics such as latency and further study of the fail-operational concept.

\section{Acknowledgments}

This work was sponsored by NASA's Aviation Safety Program (AvSP), Vehicle Systems Safety Technologies project, led by Paul Krasa. The authors would like to thank the civil servants and contractors in NASA Langley's Simulation Development Branch who provided excellent simulation development, maintenance, and execution in support of our experiment. In particular, the work of Mr. Ben Lewis of Unisys Corp. in developing a real-time physicsbased MMWR simulation capability was key to the success of this work. The results of his work were outstanding. The support and advice from Mr. Glenn Connor, Discover Technologies, Mark Humphries, FAA, and Mr. Kevin Burnett and Mr. Jack Cross, Sierra Nevada Corporation was greatly appreciated.

\section{References}

${ }^{1}$ Joint Planning and Development Office, 2008, Next Generation Air Transportation System Integrated Plan: A Functional Outline, Washington, DC.

${ }^{2}$ Federal Aviation Administration, Instrument Flight Procedures (IFP) Inventory Summary, Retrieved April 27, 2015 from http://www.faa.gov/air traffic/flight info/aeronav/ifpinventorysummary.

${ }^{3}$ Arthur, J. J., III, Prinzel, L. J., III, Kramer, L. J., Bailey, R. E., and Parrish, R. V. (2003). CFIT prevention using synthetic vision. Proceedings of SPIE, Enhanced and Synthetic Vision 2003, 5018, 146-157.

${ }^{4}$ Schiefele, J., Howland, D., Maris, J., Pschierer, C., Wipplinger, P., and Meuter, M. (2005) Human factors flight trial analysis for 3D SVS: Part II. Proceedings of SPIE, Enhanced and Synthetic Vision 2005, 5802, 195-206.

${ }^{5}$ Kramer, L. J., Prinzel, L. J., III, Bailey, R. E., and Arthur, J. J., III (2003). Synthetic vision enhances situation awareness and RNP capabilities for terrain-challenged approaches. Proceedings of the American Institute of Aeronautics and Astronautics Third Aviation Technology, Integration, and Operations Technical Forum, AIAA 2003-6814, 1-11.

${ }^{6}$ French, G. and Schnell, T. (2003). Terrain awareness \& pathway guidance for head-up displays (TAPGUIDE): a simulator study of pilot performance. Proceedings of 22nd IEEE/AIAA Digital Avionics Systems Conference, 2, pp. 9.C.4 - 9.1-7.

${ }^{7}$ Schnell, T., Keller, M., and Etherington, T. (2009). Trade-offs in synthetic vision systems display resolution, field of regard, terrain data density, texture, and shading during off path operations. The International Journal of Aviation Psychology, pp. 33-48.

${ }^{8}$ Lemos, K. and Schnell, T. (2003). Synthetic vision systems: human performance assessment of the influence of terrain density and texture. Proceedings of 22nd IEEE/AIAA Digital Avionics Systems Conference, 2, pp. 9.E.3 - 91-10.

${ }^{9}$ Alexander, A. L., Wickens, C. D., and Hardy, T. J. (2005). Synthetic vision systems: the effects of guidance symbology,

American Institute of Aeronautics and Astronautics 
${ }^{10}$ Kramer, L. J., Williams, S. P., and Bailey, R. E. (2008). Simulation evaluation of synthetic vision as an enabling technology for equivalent visual operations. Proceedings of SPIE, Enhanced and Synthetic Vision Conference 2008, 6957, 1-15.

${ }^{11}$ McKenna, Ed. "Synthetic Vision Systems." Avionics Magazine, May 2012, pp. 20-23.

${ }^{12}$ Connor, Glenn. "On the Road to Zero-Zero.” Professional Pilot Magazine, April 2011.

${ }^{13}$ Minimum Aviation System Performance Standards (MASPS) for Enhanced Vision Systems, Synthetic Vision Systems, Combined Vision Systems and Enhanced Flight Vision Systems. RTCA/DO-315, RTCA Inc. Washington, DC. Dec 2008.

${ }^{14}$ Federal Aviation Administration, Revisions to Operational Requirements for the Use of Enhanced Flight Vision Systems (EFVS) and to Pilot Compartment View Requirements for Vision Systems, Retrieved April 27, 2015 from https://federalregister.gov/a/2013-13454.

${ }^{15}$ Glenn Connor. NASA studies advanced EFVS sensor models with dual HUD flightdeck for landing in $300 \mathrm{ft}$ RVR. Professional Pilot. October 2014, pp. 98-102.

${ }^{16}$ Bailey, R. E., Kramer, L. J., and Williams, S. P. (2010). Enhanced vision for all-weather operations under NextGen. Proceedings of SPIE Enhanced and Synthetic Vision Conference 2010, 7689, pp. 768903-1-768903-18.

${ }^{17}$ Kramer, L. J., Harrison, S. J., Bailey, R. E., Shelton, K. J., and Ellis, K. K. (2014). Visual advantage of enhanced flight vision system during NextGen flight test evaluation. Proceedings of SPIE Degraded Visual Environments: Enhanced, Synthetic, and External Vision Solutions 2014, 9087, pp. 90870G-90870G-18.

${ }^{18}$ Minimum Aviation System Performance Standards (MASPS) for an Enhanced Flight Vision System to Enable All-Weather Approach, Landing and Roll-Out to a Safe Taxi Speed. RTCA/DO-341, RTCA Inc. Washington, DC. Sept 2012.

${ }^{19}$ Kramer, L. J., Bailey, R. E., Ellis, K. K., Williams, S. P., Arthur, J. J., III, Prinzel, L. J., III, \& Shelton, K. J. (2013). Enhanced flight vision systems and synthetic vision systems for NextGen approach and landing operations (NASA Technical Publication 218054). Washington, DC: NASA

${ }^{20}$ Etherington, T. J., Kramer, L. J., Severance, K., Bailey, R. E., Williams, S. P., and Harrison, S. J. (2015). Enhanced flight vision systems opeational feasibility study using radar and infrared sensors. Proceedings of the 34th Digital Avionics Systems Conference.

${ }^{21}$ Ames, Lawrence L. \& George, Edward J. (1993). Revision and verification of a seven-point workload estimation scale. Air Force Flight Test Center: AFFTC-TIM-93-01.

${ }^{22}$ Vidulich, M. A. and Hughes, E. R. (1991). Testing a subjective metric of situation awareness. Proceedings of the Human Factors \& Ergonomics Society, 35th Annual Meeting, 1307-1311.

${ }^{23}$ Federal Aviation Administration Advisory Circular: Criteria for Approval of Category III Weather Minima for Takeoff, Landing, and Rollout, AC-120-28D, Dated July 13, 1999.

${ }^{24}$ European Aviation Safety Agency, Joint Aviation Requirements, All-Weather Operations. Amendment 4, Dated February, 2007.

American Institute of Aeronautics and Astronautics 